\title{
Drought-induced Leaf Senescence and Horticultural Performance of Transgenic $P_{\mathrm{SAG12}}-\mathrm{IPT}$ Petunias
}

\author{
David G. Clark, ${ }^{1}$ Chris Dervinis, and James E. Barrett \\ Department of Environmental Horticulture, University of Florida, Gainesville, FL 32611-0670 \\ Harry Klee \\ Department of Horticultural Sciences, University of Florida, Gainesville, FL 32611-0690 \\ Michelle Jones \\ Department of Horticulture and Crop Science, The Ohio State University, Wooster, OH 44691-4096
}

Additional index words. Petunia $\times$ hybrida, cytokinin synthesis, isopentenyl transferase, transgenic plants

\begin{abstract}
Cytokinins have been shown to delay the onset of leaf senescence. The focus of this project was to produce transgenic petunia (Petunia $\times$ hybrida) plants that over-produced endogenous cytokinins in a senescence specific manner. This was achieved by transforming plants with the IPT (isopentenyl transferase) gene driven by the senescence-associated transcriptional promoter, $\mathbf{P}_{\mathrm{SAG} 12}$. Two independent transgenic events produced $\mathbf{T}_{1}$ and $\mathbf{T}_{2}$ generation seedling lines that demonstrated the desired nonsenescent phenotype in progeny trials. These lines were used to evaluate the horticultural performance of $\mathrm{P}_{\mathrm{SAG12}}-I P T$ petunia plants in terms of delayed senescence, rooting of vegetative cuttings, lateral branch growth, flower number, floral timing, and fruit set. Although both lines displayed a delayed senescence phenotype the two $P_{\mathrm{SAG}_{12}}-I P T$ transgenic lines differed from each other in regard to other horticultural traits. In addition to delayed leaf senescence, line I-1-7 also demonstrated a decrease in adventitious rooting and an increased number of branches during plant production. Line I-3-18 also demonstrated a delayed leaf senescence phenotype; however, plants of this line were not greatly altered in any other horticultural performance traits in comparison to wild-type 'V26'. IPT transcript was detected in young fully expanded leaves of both lines, although mRNA levels were higher in I-1-7 plants. A greater than 50-fold increase in IPT transcript abundance was detected in leaves of transgenic plants following drought stress. These results demonstrate that it is possible to use $P_{\mathrm{SAG12}}-I P T$ to produce transgenic plants with delayed leaf senescence but differences in plant morphology between transgenic lines exist, which may alter horticultural performance characteristics.
\end{abstract}

Senescence is the final developmental process in the lifecycle of a leaf. It is a process through which the nutrients contained within the macromolecules (e.g., chlorophyll, proteins, nucleic acids) of leaf cells are metabolized to basic components and transported to the growing shoot and reproductive organs of the plant. This strategy imparts a survival advantage for plants that grow under adverse conditions where nutrients are limiting (Noodén, 1988). Natural leaf senescence in many plants is characterized by yellowing or chlorosis of the lower leaves as nutrients and other components of the cells are degraded (esp. chlorophyll). In horticultural terms, chlorosis can decrease the aesthetic appearance and thereby decrease the salability of that plant. With so much at risk, it is no wonder that growers and researchers alike have tried to understand the components of leaf senescence in order to prevent it.

One way to prevent leaf senescence is through the manipulation of cytokinins. Cytokinins are an important class of plant hormones that influence numerous aspects of plant growth and development. They have been shown to delay and, in some cases, reverse the leaf senescence process (Gan and Amasino, 1996). There is an inverse correlation between the concentration of cytokinins in leaves and the magnitude of leaf senescence. This can be dramatically seen as the formation of green islands on leaves infected by cytokinin-producing pathogens, such as Helminthosporium teres (Angra and Mandahar, 1991). The use of applied cytokinins to prevent senescence is limited because it is difficult to supply them

Received for publication 22 Apr. 2003. Accepted for publication 4 Aug. 2003. Florida Agricultural Experiment Station journal series R-09683. This research was funded by grants from The Fred C. Gloeckner Foundation Inc., The American Floral Endowment and the Florida Agricultural Experiment Station.

${ }^{1}$ Corresponding author. to the appropriate cellular location at the proper concentrations needed to affect senescence. Exogenously applied cytokinins may not enter the cells, may not be transported to the area needed, or may quickly become conjugated or metabolized to nonactive forms (Gan and Amasino, 1996; Kaminek et al., 1997; Klee and Lanahan, 1995). Researchers have recently turned to manipulation and engineering of metabolism to solve these problems.

Although senescence was once thought to be a chaotic process that involved the shut down of gene expression, it is now recognized to be a highly regulated process that requires the de novo synthesis of many nuclear genes, often referred to as senescence-associated genes (SAGs) (Buchanan-Wollaston, 1997; Weaver et al., 1998). In Arabidopsis and other plants, expression of SAGs increased under conditions that evoked leaf senescence and some of the SAGs were found to encode enzymes responsible for the catabolism and mobilization of the senescing cell's contents (Buchanan-Wollaston, 1997; Lohman et al., 1994; Weaver et al., 1998). Both senescence and SAGs can be induced by many different environmental and endogenous stimuli such as age, drought stress, nutrient deficiencies, fruit development, and hormone concentration. However, the SAGs do not respond to the different senescence-inducing cues in the same way. For example, when Arabidopsis rosettes were cut at their bases and allowed to dry for $3 \mathrm{~h}$, SAGs 14, 17, 20, and 21 were all induced directly in response to drought stress while SAG 12 was not (Weaver et al., 1998). Of all the SAGs known to date, SAG 12 is thought to be the most specific for natural senescence. It shows no detectable expression in young leaves and does not accumulate until the leaf becomes $20 \%$ chlorotic (Weaver et al., 1998).

After many years of research on cytokinins, the mechanisms of plant cytokinin biosynthesis and perception are just now be- 
ing elucidated. One enzyme, isopentenyl transferase (IPT), has received much research attention because of its known involvement in cytokinin synthesis. Although it is well-known that there is IPT activity in plants, the genes that encode IPT have only recently been isolated and cloned from plants (Kakimoto, 2001; Takei et al., 2001). Therefore analysis of transgenic plants with altered expression of these genes is just now being conducted. In contrast, a gene from Agrobacterium tumefaciens that encodes the IPT enzyme has been available for use in transgenic plant research for a number of years. The tmr locus encoding isopentenyl transferase is located on the Ti (tumor inducing) plasmid of Agrobacterium tumefaciens (Akiyoshi et al., 1984; Barry et al., 1984). It catalyzes the condensation of dimethylallylpyrophosphate (DMAPP) and 5'AMP to form isopentenyladenosine 5'-phostphate ([9R-5'P]iP), which is then converted to multiple forms of cytokinins. The condensation of DMAPP and 5'AMP to [9R-5'P]iP is presumed to be the rate-limiting step in cytokinin biosynthesis since expression of this one gene can cause an overproduction of cytokinins (Gan and Amasino, 1996; Klee and Lanahan, 1995; Medford et al., 1989). Attempts have been made to use this gene under the control of various promoters [e.g., modified CaMV 35S (Faiss et al., 1997), $\mathrm{Cu}^{2+-i n d u c i b l e ~(M c K e n z i e ~}$ et al., 1998), or heat shock inducible (Smart et al., 1991)] to stop leaf senescence. However, the results of such experiments were often complicated by abnormal growth patterns, or the possibility that the induction treatment (i.e. high temperature or $\mathrm{CuSO}_{4}$ treatment) was causing the observed phenotype (Buchanan-Wollaston, 1997; Smart et al., 1991).

In an attempt to overcome the problems associated with the overproduction of cytokinins in transgenic plants, Gan and Amasino (1995) developed a genetic construct that used the highly senescence specific promoter from SAG $12\left(\mathrm{P}_{\mathrm{SAG}-12}\right)$ to drive $I P T$ expression. This $\mathrm{P}_{\mathrm{SAG}-12}-I P T$ construct had three important features: temporal regulation, spatial regulation, and quantitative regulation (Gan and Amasino, 1995, 1996). In other words, when leaf senescence is triggered, the transcription of IPT is activated by $\mathrm{P}_{\mathrm{SAG}-12}$, leading to the production of functional enzyme. The enzyme then catalyzes cytokinin production, which in turn delays senescence. Without senescence signals, the $\mathrm{P}_{\mathrm{SAG}-12}$ promoter attenuates IPT transcription and subsequent enzyme production, thus providing autoregulatory control of cytokinin synthesis. The $\mathrm{P}_{\mathrm{SAG}-12}-I P T$ construct was transformed into tobacco (Nicotiana tabacum 'Wisconsin'), and plants displayed a normal growth habit except for a delay in leaf senescence. Other phenotypic alterations included increased number of flowers, increased biomass (due to the presence of lower leaves) and increased seed-yield (Gan and Amasino, 1995).

The purpose of this work was to evaluate the benefits of $\mathrm{P}_{\mathrm{SAG}_{12}}$ $I P T$ to the floriculture industry. This was accomplished through the transformation of Petunia $\times$ hybrida 'V26' with $\mathrm{P}_{\mathrm{SAG}_{2}-I P T}$. Transformed plants were selected for delayed leaf senescence, then characterized in terms of their horticultural performance in the areas of leaf senescence, adventitious root formation, flower timing, seed production, number of branches, number of flowers and biomass accumulation.

\section{Materials and Methods}

Plant Materials AND TRANSFORmation. Leaf explants from 56 day-old 'V26' seedlings were transformed with pSG529 obtained from Rick Amasino (Gan and Amasino, 1995) according to the methods described by Jorgensen et al. (1996). Transformation was conducted four separate times, and the time from explant inoculation to transformed greenhouse plant was $\approx 3$ months for each experiment. Nineteen rooted plants were transferred to 6-cell-packs $(70 \mathrm{~mL} / \mathrm{cell})$ that contained Fafard 2 mix (Fafard Co., Apopka, Fla.). These $\mathrm{T}_{0}$ plants were then given identification numbers based on the transformation group and event. For example, plant I-1-7 was the seventh transformation event in the first transformation group.

Plant growth and Selection. After transplanting into soilless media (Fafard 2, Apopka, Fla.), $\mathrm{T}_{0}$ plants were acclimated under intermittent mist, then grown in a fan and pad cooled greenhouse programmed to vent at $22{ }^{\circ} \mathrm{C}$ and heat at $16^{\circ} \mathrm{C}$. Plants were fertilized with $150 \mathrm{mg} \cdot \mathrm{L}^{-1} 20 \mathrm{~N}-4.8 \mathrm{P}-16 \mathrm{~K}$ Peter's soluble fertilizer (Scotts Inc., Marysville, Ohio) at every irrigation for 1 month. Plants were then potted in 5.2-L pots, and fertilized at the same rate on every other irrigation. Plants were treated monthly with Cleary's Thiophanate (W.A. Cleary Chemical Co., Somerset, N.J.) to control fungal growth.

$\mathrm{T}_{0}$ plants (4 months old) were grown until wild-type control plants displayed natural senescence of their lower leaves. Two independent $\mathrm{T}_{0}$ plants tested positive using ELISA (described below) and also had a delayed leaf senescence phenotype. These two transgenic lines (I-1-7 and I-3-18) were subsequently selected and self-pollinated to produce $\mathrm{T}_{1}$ generation plants for the experiments described here. One seed per cell from each of the two selected lines and 'V26' were sown on top of soilless mix (Fafard 2) in 6-cell packs $(70 \mathrm{~mL} /$ cell $)$ and placed under intermittent mist $(5 \mathrm{~s} / 30 \mathrm{~min})$ for $3 \mathrm{~d}$. Seedlings were then moved to a double polyhouse, covered with vermiculite and misted by hand with tap water as needed. After 4 weeks, the plants were potted in 1.5-L pots and fertilized once per week with $300 \mathrm{mg} \cdot \mathrm{L}^{-1}$ Peter's $15 \mathrm{~N}-2.2 \mathrm{P}-12.3 \mathrm{~K}$ and with tap water at other irrigations.

In an effort to obtain plants homozygous for the transgene eight individual I-1-7 and I-3-18 $\mathrm{T}_{1}$ progeny showing a delayed leaf senescence phenotype were self-pollinated to produce the $\mathrm{T}_{2}$ generation. Upon ELISA analysis of these progeny, none of these $T_{2}$ families proved to be homozygous because none of the families had $100 \%$ of the progeny testing positive for the presence of the IPT transgene. Positive and negative segregants from three $T_{2}$ sibling families from I-1-7 and two $T_{2}$ families from I-3-18 were selected for subsequent leaf senescence and horticultural performance experiments, and grown as described above. These families were selected because they demonstrated consistent leaf senescence phenotypes in the $T_{1}$ generation and gave the best germination in a preliminary seed germination test (data not shown). All plants in the senescence screening experiments were grown from seed as described above. Plants used in horticultural performance experiments were treated with a tank mix of 1,250 ppm daminozide (B-Nine; Uniroyal Chemical Co, Middlebury, Conn.) and 1,250 ppm chloromequat chloride (Cycocel; Cyanamid, Wayne, N.J.) at 4 weeks and again at 8 weeks during production to control plant height.

ENZYME-LINKED IMMUNOSORBENT ASSAYS (ELISAs). ELISAS were performed on the $T_{1}$ and $T_{2}$ crops to determine if they contained the transgene. ELISAs for the NPTII gene product were performed using the PathoScreen NPTII system according to the manufacturer's instructions (Agdia, Inc., Elkhart, Ind.). Samples were read at an absorbance of $450 \mathrm{~nm}$ with a plate reader (Spectramax 250; Molecular Devices, Sunnyvale, Calif.) and deemed to be positive for the transgene if the NPTII protein was detected at levels above wild-type controls, and negative if the NPTII protein was detected at control levels. Of the individual 
plants tested, heterozygous and homozygous plants could not be distinguished using this assay based on NPTII levels.

QUANTITATIVE REVERSE TRANSCRIPTION POLYMERASE CHAIN REACTION (QRT-PCR). Fully expanded green leaves and lower leaves from 3 -month-old plants were collected after $24 \mathrm{~h}$ of visible wilting following drought stress and frozen in liquid $\mathrm{N}_{2}$. Total RNA was extracted using TRIZOL reagent (Gibco BRL, Rockville, Md.). RNA samples were treated with RQ1 RNAse-free DNase (Promega, Madison, Wis.) to remove any contaminating genomic DNA and quantified using a spectrophotometer (DU 640; Beckman Coulter, Fullerton, Calif.). Relative abundance of the IPT transcript was determined using quantitative (real-time) reverse transcription polymerase chain reaction (qRT-PCR). Five hundred fifty nanograms of RNA was reverse transcribed and amplified using the QuantiTect SYBR Green RT-PCR kit (Qiagen, Valencia, Calif.). Using the DNA Engine Opticon continuous fluorescence detector (MJ Research Incorporated, Boston, Mass.) RNA was reverse transcribed for $30 \mathrm{~min}$ at $50^{\circ} \mathrm{C}$. Following activation of the HotStar Taq DNA polymerase at $95^{\circ} \mathrm{C}$ for $15 \mathrm{~min}$, PCR was conducted for 35 cycles of denaturation at $94^{\circ} \mathrm{C}$ for $15 \mathrm{~s}$, annealing at $55^{\circ} \mathrm{C}$ for $30 \mathrm{~s}$, and elongation at $72{ }^{\circ} \mathrm{C}$ for $30 \mathrm{~s}$. Relative amounts of transcript were determined by comparing the products to an external standard RNA curve (Lightcycler Control RNA Kit; Roche Diagnostics, Mannheim, Germany). Actin was amplified as an endogenous control to standardize the amount of sample RNA added to each reaction. Primers were constructed to amplify 152- and 176-bp amplicons of IPT and actin respectively. The primers included $I P T$ forward 5' -GCC TCT GGT GAA GGG TAT CA-3', IPT reverse 5'-CCG CAC TCC AAT AAC TGC TT-3', actin forward 5'-TTG TCC GTG ACA TGA AGG AA-3' and actin reverse 5'-TCGATGGCTGGAAGAGAACT-3'. Samples were run in triplicate and data presented is the mean of the three replications \pm SEM

DROUGHT-INDUCED LEAF SENESCENCE. Leaf senescence was induced in petunia by drought stress. In an effort to quantify the delayed leaf senescence phenotype, $T_{2}$ generation transgenic plants and 'V26' plants were grown for 11 weeks as described previously (just before showing visible flower color). The plants were watered to media saturation, then no further irrigation was provided until the plants wilted from drought stress. After a 24$\mathrm{h}$ period of visible wilting, plants were irrigated with fertilizer solution, then they were maintained well-watered for $14 \mathrm{~d}$. All plants showed visible signs of wilting within $24 \mathrm{~h}$ of each other. At that time, the total number of completely chlorotic leaves was counted. Leaves showing any signs of senescence that were not completely chlorotic were counted separately in order to help illustrate the overall phenotype of the plants. The experiment was arranged in four randomized complete blocks that consisted of six ELISA positive and three ELISA negative plants per genotype, and six 'V26' plants per block. The experiment was replicated at the same time in an identical greenhouse.

Analysis of leaf senescence was also conducted by extraction of chlorophyll in the lower leaves of drought-stressed $\mathrm{T}_{2}$ and 'V26' plants. To extract chlorophyll, six $0.36-\mathrm{cm}^{2}$ leaf disks (a total of $2.16 \mathrm{~cm}^{2}$ ) were collected from mature leaves located on the lower one-half of the plant. Leaf disks were placed in $10 \mathrm{~mL}$ of $95 \% \mathrm{EtOH}$ at $4{ }^{\circ} \mathrm{C}$ for $24 \mathrm{~h}$. After extraction, the amounts of chlorophyll $\mathrm{a}, \mathrm{b}$, and $\mathrm{a}+\mathrm{b}$ were determined by the methods of Wintermans and De Mots (1965) using a Spectronic 20 spectrophotometer (Baush and Lomb, Rochester, N.Y.) at absorbance wavelengths of 649,654 , and $665 \mathrm{~nm}$. Chlorophyll was extracted from leaf tissue collected on the same plants one day prior to wilt, $3 \mathrm{~d}$ after wilt (DAW), 5 DAW, and 7 DAW on six plants per genotype per sampling date. The data for leaf senescence and total chlorophyll concentration were analyzed by calculating the means and standard errors using the SAS means procedure (SAS 6.0, SAS Insitute, Cary, N.C.).

Floral timing, lateral branching, AND Flowering. To determine if $\mathrm{P}_{\mathrm{SAG}_{12}}-I P T$ affected the timing of floral induction, lateral branching, and number of flowers per plant, $\mathrm{T}_{2}$ generation plants were grown as described above in four randomized complete blocks. Each block consisted of six ELISA positive plants, three ELISA negative plants, and six 'V26' wild-type plants, and the experiment was replicated at the same time in an identical greenhouse. The first flower on each plant was tagged at anthesis and the number of days from seed sowing to anthesis was calculated. Means and standard errors were generated for the number of days to flowering for each genotype using the SAS means procedure.

At 15 weeks after seed sowing, the number of branches longer than $8 \mathrm{~cm}$ and the number of flowers per plant were counted to determine if $\mathrm{P}_{\mathrm{SAG} 12}-I P T$ influenced gross morphology. $\mathrm{T}_{2}$ plants arranged in four randomized complete blocks that consisted of six ELISA positive plants, three ELISA negative plants per genotype, and six 'V26' wild-type plants per block were grown as described previously. Means and standard errors for the number of days from seed sowing to anthesis of the first flower and the number of branches and flowers were generated for each genotype using the SAS means procedure.

Adventitious root Formation. To study the effects of $\mathrm{P}_{\mathrm{SAG} 12^{-}}$ $I P T$ on adventitious root formation, vegetative cuttings were taken from 10-week-old $T_{2}$ and 'V26' plants. Four cuttings per plant were taken from 24 ELISA positive plants (96 total cuttings) and 12 ELISA negative plants (48 total cuttings) of each genotype, and from 24 'V26' plants (96 total cuttings). The cuttings were then divided into two groups. One group was stuck in 6-packs $(70 \mathrm{~mL} / \mathrm{cell})$ that contained perlite:Fafard $2 \mathrm{mix}(2: 1)$. The other group was treated with 1000 ppm IBA(Rhizophon AA\#1, Hortus USA Corp., New York) and propagated identically. The 6-packs were then arranged in four randomized complete blocks with each block containing 24 ELISA positive cuttings and 12 ELISA negative cuttings from each genotype and 24 'V26' cuttings. The cuttings were placed in the mist house under an intermittent mist of $5 \mathrm{~s} / 20 \mathrm{~min}$. After $14 \mathrm{~d}$, the numbers of adventitious roots per cutting were counted. Means and standard errors for the number of adventitious roots per cutting were generated using SAS.

\section{Results and Discussion}

Plant Selection and transgene Segregation. After transforming 'V26' explants with $\mathrm{P}_{\mathrm{SAG} 12}-I P T$, a wide range of plant phenotypes was observed in the $\mathrm{T}_{0}$ generation. Many plants had delayed leaf senescence; some of these plants were highly branched and had significantly delayed flowering, while others had whole plant morphologies similar to 'V26', except they had a delayed senescence phenotype. This initial observation suggested to us the possibility of a lack of tight control of IPT expression by the $\mathrm{P}_{\mathrm{SAG} 12}$ promoter in transgenic petunias. We selected two lines (I1-7 and I-3-18) for further research because they had whole-plant morphologies that were very similar to 'V26' plants, but they also had a delayed senescence phenotype. Based on $\mathrm{T}_{2}$ segregation patterns, it was determined that both of these lines had a single copy of the transgene inserted into their genomes (Table 1). The $\mathrm{T}_{2}$ segregation patterns were determined based on ELISA results 
for the NPTII gene product. ELISA positives and negatives were tabulated and a chi-squared analysis performed to test for 3:1 and 1:1 segregation patterns (Table 1). Families I-1-7-1, I-1-7-2, and I-1-7-3 segregated as 143:50 (positive: negative), 157:43, and 145:55 respectively, which fits closely to the expected $3: 1$ segregation ratio. The $\chi^{2}$ values for these families ranged between 0.54 and 1.13, which gives good supporting evidence for the 3: 1 segregation pattern of a single dominant gene (Table 1). Consistent with observations in the $\mathrm{T}_{1}$ generation (data not shown), the $\mathrm{T}_{2}$ families I-3-18-1 and I-3-18-2 followed a 1:1 segregation pattern. I-3-18-1 segregated as 92:108 (positive: negative) and I-3-18-2 segregated as 89:111, which gives $\chi^{2}$-values of 1.12 and

Table 1. $\chi^{2}$ values for transgene segregation ${ }^{\mathrm{z}}$ in $\mathrm{P}_{\mathrm{SAG} 12}-I P T$ petunias for a 3:1 or 1:1 ratio in the $T_{2}$ population.

\begin{tabular}{lcccc}
\hline Genotype & Positive & Negative & $\begin{array}{c}\chi^{2} \\
(3: 1)\end{array}$ & $\begin{array}{c}\chi^{2} \\
(1: 1)\end{array}$ \\
\hline I-1-7-1 & 143 & 50 & $1.13^{* * *}$ & $36.13^{*}$ \\
I-1-7-2 & 157 & 43 & $1.13^{* * *}$ & $63.85^{*}$ \\
I-1-7-3 & 145 & 55 & $0.54^{* * *}$ & $39.61^{*}$ \\
I-3-18-1 & 92 & 108 & $88.17^{*}$ & $1.12^{* * * *}$ \\
I-3-18-2 & 89 & 111 & $97.61^{*}$ & $2.21^{* *}$ \\
\hline
\end{tabular}

${ }^{z} T_{2}$ segregation was determined by ELISA for the NPT II gene product, and analysis of leaf senescence. All positive plants had detectable NPTII gene product and delayed leaf senescence, while all negative plants had no detectable NPTII gene product and normal leaf senescence.

*,**,***,**** Significant probability that there was a deviation from the expected values as large or larger than what was observed due to chance alone, where the null hypothesis is that the population is segregating at the indicated ratio at $p<0.001,0.25>p>0.1,0.5>p>0.25$, or 0.75 $>p>0.5$, respectively.

Table 2. Ipt transcript abundance as determined by quantitative RT-PCR. Relative mRNA levels determined by comparison to an external standard curve and normalized using actin as an endogenous control.

\begin{tabular}{lcc}
\hline Genotype & Treatment & Relative ipt mRNA level $\left(\times 10^{-4}\right)$ \\
\hline V26 & No stress & $0.124 \pm 0.00594$ \\
V26 & $\mathrm{H}_{2} \mathrm{O}$ stress & $0.121 \pm 0.0136$ \\
$\mathrm{I}-1-7$ & No stress & $4.24 \pm 0.479$ \\
$\mathrm{I}-1-7$ & $\mathrm{H}_{2} \mathrm{O}$ stress & $226.57 \pm 17.49$ \\
$\mathrm{I}-3-18$ & No stress & $2.43 \pm 0.297$ \\
$\mathrm{I}-3-18$ & $\mathrm{H}_{2} \mathrm{O}$ stress & $157.99 \pm 11.49$ \\
\hline
\end{tabular}

Table 3. Mean number (+SE) of senescing and chlorotic leaves. Leaves were examined from 'V26' and positive and negative ELISA segregants from sibling populations of the $\mathrm{P}_{\mathrm{SAG} 12}-I P T$ transgenic lines I-1-7 and I-3-18. Data were taken $14 \mathrm{~d}$ after recovery from drought stress treatments.

\begin{tabular}{lccc}
\hline Genotype & ELISA & $\begin{array}{c}\text { Senescing } \\
\text { leaves } \\
\text { (no.) }\end{array}$ & $\begin{array}{c}\text { Chlorotic } \\
\text { leaves } \\
\text { (no.) }\end{array}$ \\
\hline V26 & Negative & $12.3 \pm 0.77$ & $6.04 \pm 0.67$ \\
I-1-7-1 & Negative & $12.0 \pm 1.48$ & $5.83 \pm 1.2$ \\
I-1-7-1 & Positive & $0.02 \pm 0.01$ & $0.00 \pm 0.00$ \\
I-1-7-2 & Negative & $8.86 \pm 1.33$ & $5.21 \pm 1.05$ \\
I-1-7-2 & Positive & $0.05 \pm 0.05$ & $0.00 \pm 0.00$ \\
I-1-7-3 & Negative & $11.5 \pm 1.17$ & $7.58 \pm 1.33$ \\
I-1-7-3 & Positive & $0.66 \pm 0.45$ & $0.52 \pm 0.36$ \\
I-3-18-1 & Negative & $6.69 \pm 1.39$ & $3.25 \pm 0.87$ \\
I-3-18-1 & Positive & $0.42 \pm 0.33$ & $0.13 \pm 0.09$ \\
I-3-18-2 & Negative & $10.0 \pm 1.16$ & $7.67 \pm 1.26$ \\
I-3-18-2 & Positive & $0.85 \pm 0.54$ & $0.46 \pm 0.46$ \\
\hline
\end{tabular}

2.21 respectively, thus supporting the segregation of 1:1 (Table 1). All ELISA positive plants in both lines showed delayed leaf senescence, and all ELISA negative plants showed normal leaf senescence. It is possible that the aberrant segregation patterns observed for I-3-18 families was a result of poor seed germination in these lines. In the genotypes I-3-18-1 and I-3-18-2, germination of $\mathrm{T}_{2}$ seeds was calculated at $46 \%$ and $48 \%$ respectively (data not shown). If the seeds that did not germinate were predominantly positive for the transgene, this could account for the discrepancy in segregation ratios. It is also possible that there could have been some uncontrolled outcrossing by a wild-type pollen source, but this scenario is highly unlikely. Normally, we observe a very low incidence of fruit set without controlled hand-pollination in the greenhouse (data not shown). When making self-pollinations for the seeds used in these experiments, forceps used in transferring pollen were dipped in $95 \%$ alcohol between pollinations to reduce the incidence of contamination. Regardless of the reason, it caused us to use segregating $\mathrm{T}_{2}$ progeny for both lines used to conduct our research.

Drought-INDUCED LEAF SENESCENCE. Researchers have used many different methods, including dark incubation, nutrient deficiency, and water stress to control the timing of leaf senescence. Each method has its benefits and limitations. Drought stress was chosen as a means of inducing leaf senescence for three reasons: 1) leaf senescence in petunias can be consistently induced by drought stress; 2) SAG12 is not induced specifically by drought stress in Arabidopsis (Weaver et al., 1998), thus any induction of the gene would not be due to the drought treatment but rather to leaf senescence itself; and 3) during commercial production, drought stress is most likely to occur in a retail environment. After conducting preliminary experiments with $\mathrm{T}_{1}$ generation plants to determine experimental parameters (data not shown), drought-induced senescence experiments were conducted with 'V26' and sibling populations of segregating $\mathrm{T}_{2}$ generation plants for each transgenic line.

Relative expression of IPT mRNA was compared in wild-type 'V26', I-3-18 and I-1-7 plants (Table 2). In young fully expanded leaves collected from plants before drought stress, very low levels of IPT transcript were detected in all leaves with basal levels higher in I-1-7 than I-3-18. Amplicon (or product) was detected in wild-type 'V26' leaves under the experimental conditions used for qRT-PCR. Melting curve analysis indicated that the product detected in 'V26' leaves was not the same as that detected in I-1-7 and I-3-18 leaves. The primers used to amplify the Agrobacterium IPT gene have no homology to sho, the IPT gene recently isolated from petunia (Zubko et al., 2002). It is therefore likely that the product detected in 'V26' leaves represents background rather than the endogenous IPT gene. Drought stress resulted in an up-regulation of $I P T$ transcript accumulation in transgenic but not wild-type leaves. Lower leaves collected after $24 \mathrm{~h}$ of wilting, before visible leaf yellowing in 'V26', had a 53- and 65-fold increase in IPT mRNAs in I-1-7 and I-3-18, respectively. The detection of IPT mRNAs in young, nonsenescing leaves of both I-1-7 and I-3-18 plants supports the idea that the SAG12 promoter is not senescence-specific in petunia, while increased IPT mRNAs following drought stress confirm that it is still resulting in the senescence up-regulated expression of IPT. Elevated cytokinin levels in nonsenescing transgenic plant tissues compared to wild type confirmed that the IPT gene detected in both I-1-7 and I-318 plants is producing a functional isopentenyl transferase gene and that the SAG12 promoter is as tightly regulated in petunia as it is in Arabidopsis (Chang et al., 2003). 


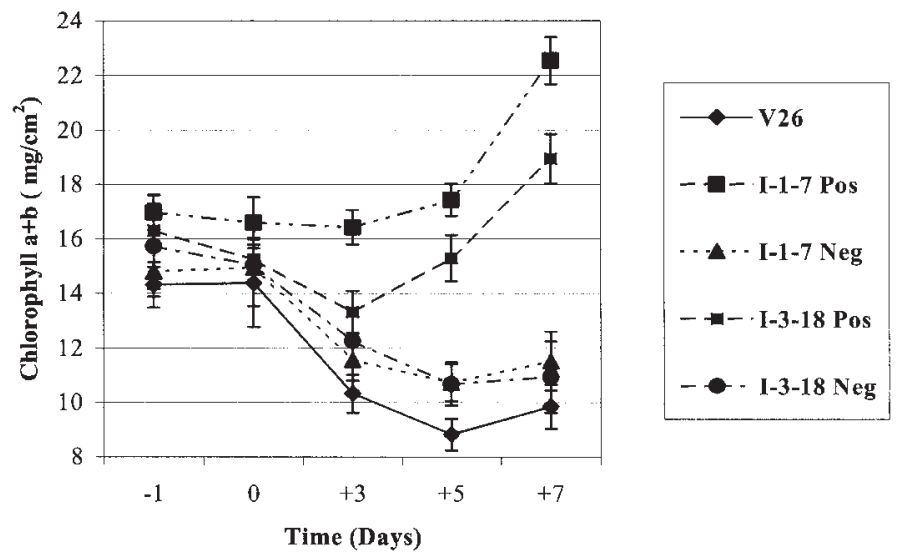

Fig. 1. Mean concentration (+SE) of chlorophyll $\mathrm{a}+\mathrm{b}$ from the lower leaves of 'V26', and positive and negative ELISA segregants from the $\mathrm{P}_{\mathrm{SAG} 12}-I P T$ transgenic lines I-1-7 and I-3-18. Chlorophyll was extracted from leaf samples were taken the day before drought stress $(-1)$, the day of wilt $(0), 3 \mathrm{~d}$ after stress $(+3), 5 \mathrm{~d}$ after stress $(+5)$, and $7 \mathrm{~d}$ after stress $(+7)$.

The $\mathrm{P}_{\mathrm{SAG} 12}-I P T$ plants showed little or no visible sign of leaf chlorosis after drought stress compared to 'V26' and the negative segregant controls from both transgenic lines (Table 3). These results clearly demonstrate that accelerated leaf senescence in Petunia $\times$ hybrida due to drought stress can be prevented by the use of the $\mathrm{P}_{\mathrm{SAG} 12}-I P T$ transgene, and that the phenotype observed is similar to that reported in tobacco (Gan and Amasino 1995) and lettuce (McCabe et al., 2001). Chloroplasts are known to breakdown during leaf senescence and chlorophyll content is often used as a measure of senescence in plants (Gan and Amasino, 1996; Lohman et al., 1994). To further characterize the effects of $\mathrm{P}_{\mathrm{SAG} 12}-I P T$ on leaf senescence in petunia, chlorophyll was extracted from the lower leaves of mature plants during drought-induced senescence. 'V26' and negative segregants showed a decline in total chlorophyll content of lower leaves over the course of the experiment (Fig. 1). Positive segregants from line I-3-18 followed the chlorophyll decline demonstrated by the controls $3 \mathrm{~d}$ after drought stress. By $7 \mathrm{~d}$, the chlorophyll $\mathrm{a}+\mathrm{b}$ content of the lower leaves of these plants increased slightly above that of pre-stress conditions. Chlorophyll content of the lower leaves of line I-1-7 did not significantly vary from the average prestress levels from days 1 through 5 and then increased to significantly higher levels by $7 \mathrm{~d}$ after drought stress treatment (Fig. 1).

Chlorophyll concentrations typically decrease during senescence (Matile et al., 1996; Noodén et al., 1997). In Arabidopsis, total chlorophyll content declines during age-related senescence (Hensel et al., 1993). The declines in the chlorophyll content observed in 'V26' and negative segregants are consistent with what is expected during normal leaf senescence. Positive segregants of line I-3-18 closely mimicked the leaf senescence of 'V26' in terms of chlorophyll degradation up to $3 \mathrm{~d}$ after drought stress and then showed a recovery of chlorophyll levels to that of pre-stressed leaves (Fig. 1). The observed increase in chlorophyll levels in lower leaves is consistent with the observations of McCabe et al. (2001), who showed that harvested $\mathrm{P}_{\mathrm{SAG} 12}-I P T$ lettuce heads retained chlorophyll in their lower leaves compared to wild-type lettuce plants.

Unlike 'V26', the chlorophyll concentration of the I-1-7 positive segregants remained consistent with pre-stress levels until day 5 and then significantly increased (Fig. 1). The higher chlorophyll levels detected in the positive segregants of I-1-7 are likely the result of the higher levels of IPT transcripts induced by drought stress in the I-1-7 plants (Table 2). Increased expression of the $I P T$ gene in young leaves of I-1-7 plants could result in higher basal cytokinin levels, which would then prevent degradation of the chlorophyll or stimulate production of new chlorophyll at a comparable level of chlorophyll degradation. When $\mathrm{P}_{\mathrm{SAG} 12}-I P T$ is induced by senescence-promoting stresses like drought, the chlorophyll levels would increase over those of the nonstressed plants. We also observed that the I-1-7 positive segregants contained more chlorophyll than the controls prior to stress induction in support of their higher basal levels of IPT transcript (Fig. 1). None of these observations are surprising when more recent work with other plant species transformed with $\mathrm{P}_{\mathrm{SAG}_{12}}-I P T$ is considered (Jordi et al., 2000; McCabe et al., 2001). In these studies reporting heterologous expression of $\mathrm{P}_{\mathrm{SAG}_{12}} I P T$ in transgenic plants, other phenotypes including reduced apical dominance, and delayed flowering have been reported in addition to delayed leaf senescence.

FLORAL TIMING, BRANCHING AND FLOWERING. The amount of time that it takes a plant to produce flowers can impact its economic value. If a floriculture crop is delayed in floral induction, then production time of those plants would increase thereby decreasing the profitability of the crop. The effects of cytokinin on floral induction have often been conflicting (Mok, 1994). For example, floral induction was delayed in tobacco expressing the IPT gene under the control of its native promoter (Piruzian et al., 1992), and also $\mathrm{P}_{\mathrm{SAG} 12}-I P T$ lettuce (McCabe et al., 2001). In contrast, the cytokinin over-producing mutant, ampl flowered in a shorter amount of time than wild-type plants (Chaudhury et al., 1993). To determine if $\mathrm{P}_{\mathrm{SAG} 12}-I P T$ affected floral timing, the number of days from the time of seed sowing to anthesis of the first flower was calculated (Table 4). The time to flowering ranged from 79 to $85 \mathrm{~d}$ on all plants (Table 4). No significant difference between the control plants ('V26' and negative segregants) and the $\mathrm{P}_{\mathrm{SAG} 12}-I P T$ plants was detected for the timing of floral induction. Therefore it can be concluded that the expression of $\mathrm{P}_{\mathrm{SAG} 12}-I P T$ has a negligible effect on floral timing, supporting the observations of Gan and Amasino (1995) in $\mathrm{P}_{\mathrm{SAG} 12}-I P T$ tobacco plants. The fact that $\mathrm{P}_{\mathrm{SAG} 12}-I P T$ has no apparent effect on floral timing lends further support to the potential benefits of controlled cytokinin production, because plants expressing the $\mathrm{P}_{\mathrm{SAG} 12}-I P T$ transgene did not show a significant delay in crop production time.

Branching habit is an important horticultural performance characteristic of ornamental plants. Increased lateral branching leads to a more compact habit, an increased number of potential

Table 4. Mean number of days (+SE) from seed sowing to anthesis of the first flower. Flowers were examined from 'V26' and positive and negative ELISA segregants from sibling populations of the $\mathrm{P}_{\mathrm{SAG} 12}-I P T$ transgenic lines I-1-7 and I-3-18.

\begin{tabular}{lcc} 
Genotype & ELISA & $\begin{array}{c}\text { Days to } \\
\text { anthesis }\end{array}$ \\
\hline V26 & Negative & $81.8 \pm 0.7$ \\
I-1-7-1 & Negative & $80.4 \pm 0.8$ \\
I-1-7-1 & Positive & $81.6 \pm 0.8$ \\
I-1-7-2 & Negative & $79.9 \pm 0.9$ \\
I-1-7-2 & Positive & $80.3 \pm 0.7$ \\
I-1-7-3 & Negative & $79.9 \pm 1.1$ \\
I-1-7-3 & Positive & $81.9 \pm 0.6$ \\
I-3-18-1 & Negative & $81.6 \pm 0.8$ \\
I-3-18-1 & Positive & $80.8 \pm 1.4$ \\
I-3-18-2 & Negative & $81.0 \pm 1.1$ \\
I-3-18-2 & Positive & $81.2 \pm 0.7$ \\
\hline
\end{tabular}


vegetative cuttings, and increased numbers of potential flowering meristems. In an effort to determine if $\mathrm{P}_{\mathrm{SAG}_{12}} I P T$ had an effect on lateral branch growth of petunias, we counted the number of branches per plant. Positive segregants of I-1-7 had more total branches (stems greater than $8 \mathrm{~cm}$ in length) per plant than I-1-7 negative segregants and 'V26' controls (Table 4). One of the two groups of sibling positive segregants of I-3-18 had significantly more branches than wild-type or negative segregants (Table 5).

The increased number of lateral branches in positive segregants may be the result of an altered cytokinin:auxin ratio due to the lack of tightly controlled expression of the $\mathrm{P}_{\mathrm{SAG} 12}-I P T$ transgene. This observation is consistent with experiments with transgenic tobacco where an increase in the cytokinin:auxin ratio was thought to be responsible for the incomplete blocking of the axillary buds in transgenic tobacco plants that expressed the IPT gene under the native promoter (Piruzian et al., 1992). The growth habit of the I-3-18 line is more consistent with the habit of wild-type plants than I-1-7. This is likely due to differences in expression of the transgene or transcript stability, or differences in cytokinin metabolism or interconversion between cytokinin forms. Future research to determine the basis of the different phenotypes shown in I-1-7 and I-3-18 should be directed to these areas.

The number of flowers that an ornamental plant produces greatly affects its economic value. To assess flower production, the numbers

Table 5. Mean number (+SE) of branches per plant and flowers per plant.

Tissues were examined from 'V26 and positive and negative ELISA segregants from sibling populations of the $\mathrm{P}_{\mathrm{SAG} 12}-I P T$ transgenic lines I-1-7 and I-3-18. Data were taken 15 weeks after seed sowing.

\begin{tabular}{lccc}
\hline Genotype & ELISA & $\begin{array}{c}\text { Branches/ } \\
\text { plant } \\
\text { (no.) }\end{array}$ & $\begin{array}{c}\text { Flowers/ } \\
\text { plant } \\
\text { (no.) }\end{array}$ \\
\hline V26 & Negative & $14.5 \pm 0.8$ & $26.6 \pm 1.9$ \\
I-1-7-1 & Negative & $15.5 \pm 1.5$ & $27.0 \pm 1.3$ \\
I-1-7-1 & Positive & $23.9 \pm 1.8$ & $29.8 \pm 3.0$ \\
I -1-7-2 & Negative & $19.0 \pm 3.1$ & $31.1 \pm 3.1$ \\
I -1-7-2 & Positive & $24.1 \pm 1.0$ & $32.3 \pm 3.1$ \\
I -1-7-3 & Negative & $14.2 \pm 1.1$ & $31.3 \pm 3.0$ \\
I -1-7-3 & Positive & $22.6 \pm 1.2$ & $41.2 \pm 2.0$ \\
I -3-18-1 & Negative & $18.8 \pm 2.0$ & $28.5 \pm 2.9$ \\
I -3-18-1 & Positive & $20.5 \pm 1.1$ & $35.6 \pm 2.1$ \\
I -3-18-2 & Negative & $15.5 \pm 1.1$ & $30.7 \pm 1.3$ \\
I -3-18-2 & Positive & $16.2 \pm 1.0$ & $31.7 \pm 1.5$ \\
\hline
\end{tabular}

Table 6. Mean number ( $+\mathrm{SE}$ ) of adventitious roots formed on vegetative cuttings taken from 10 week-old stock plants. Cuttings from 'V26' and positive and negative ELISA segregants from sibling populations of the $\mathrm{P}_{\mathrm{SAG} 12}-I P T$ transgenic lines I-1-7 and I-3-18 were propagated for 2 weeks.

\begin{tabular}{lccc}
\hline & & \multicolumn{2}{c}{ Roots/cutting } \\
\cline { 3 - 4 } Genotype & ELISA & $(-\mathrm{IBA})$ & $(+\mathrm{IBA})$ \\
\hline V26 & Negative & $23.2 \pm 2.9$ & $27.3 \pm 2.9$ \\
I-1-7-1 & Positive & $10.4 \pm 1.9$ & $15.9 \pm 2.2$ \\
I-1-7-1 & Negative & $24.2 \pm 2.8$ & $26.9 \pm 3.1$ \\
I-1-7-2 & Positive & $4.85 \pm 1.5$ & $14.9 \pm 1.6$ \\
I-1-7-2 & Negative & $26.2 \pm 2.8$ & $29.2 \pm 2.3$ \\
I-1-7-3 & Positive & $2.8 \pm 1.0$ & $5.3 \pm 1.6$ \\
I-1-7-3 & Negative & $12.1 \pm 2.5$ & $18.2 \pm 2.0$ \\
I-3-18-1 & Positive & $20.6 \pm 2.1$ & $22.2 \pm 2.1$ \\
I-3-18-1 & Negative & $26.6 \pm 3.4$ & $31.3 \pm 3.2$ \\
I-3-18-2 & Positive & $15.9 \pm 2.8$ & $24.6 \pm 2.2$ \\
I-3-18-2 & Negative & $21.0 \pm 3.6$ & $31.9 \pm 2.8$ \\
\hline
\end{tabular}

of open flowers were counted on all plants at 15 weeks after seed sowing. Positive segregants from two of the three sibling populations from the transgenic line I-1-7 and both sibling populations from line I-3-18 had slightly more flowers than wild-type 'V26' plants (Table 5). However, positive segregants did not always have significantly more flowers than negative segregants of the same population (Table 5). It was apparent that any increases observed for the number of flowers per plant certainly did not reflect the magnitude of differences in branching habit observed on these plants (Table 5). Gan and Amasino (1995) reported an increase in the number of flowers in tobacco transformed with the $\mathrm{P}_{\mathrm{SAG} 12}-I P T$ construct. One key difference between that experiment and our experiment was that they counted the combined number of flowers produced throughout the life of the plant, rather than the number of flowers at a given point in time. Tobacco has a determinant pattern of growth, flowering once, then entering senescence to support floral and seed development. During the course of the experiment, the wild-type tobacco plants stopped producing flowers, but the transgenic tobacco plants continued to produce flowers after the experiments were terminated (Gan and Amasino, 1995). Petunia has an indeterminant growth pattern and thus continues to produce new flowers throughout its life. It is possible that the number of flowers could differ at times later in plant development if the plants are observed for an extended period of time. It is also possible that any potential large increases in flower number would result in the production of smaller-sized flowers. Future experiments should be conducted to determine whether the total production of flowers varies throughout the entire lifecycle of these plants in order to address long-term performance of these plants in the landscape.

Adventitious root formation. A comprehensive rooting experiment was performed on cuttings taken from $\mathrm{T}_{2}$ generation plants. Vegetative cuttings were rooted with and without 1000 ppm IBA (Rhizophon AA\#1, Hortus USA Crop., New York). This treatment was used to determine if treatment with auxin could overcome the decrease in adventitious root formation observed in preliminary experiments on $\mathrm{T}_{1}$ plants (data not shown). 'V26' and the negative segregants had similar numbers of adventitious roots per cutting, both with and without IBA treatment (Table 6). The positive segregants of I-1-7 showed a decrease in adventitious rooting compared to 'V26' and their negative segregants. Although auxin (IBA) treatment did increase the amount of adventitious roots formed by I-1-7 cuttings, they never produced as many roots as cuttings taken from nontreated control plants (Table 6).

Regardless of auxin treatment, cuttings taken from the positive segregants of I-3-18 had more adventitious roots than cuttings taken from positive segregants of I-1-7, and slightly fewer cuttings than wild-type 'V26' (Table 6). These results are consistent with our finding that I-3-18 plants have lower basal levels of transgene expression than I-1-7. The result that an overproduction of endogenous cytokinins can cause decreased rooting of vegetative cuttings is consistent with previous studies that showed that plants that overproduced cytokinins had inhibited root growth (Gan and Amasino, 1996). Interestingly, we have observed that normal below-ground root growth is also inhibited in I-1-7 plants compared to I-3-18 and 'V26' plants (data not shown). However, we have not grown these plants in a sand culture or hydroponic root growth systems that would allow for accurate root measurements.

\section{Conclusions}

Our experiments demonstrate the potential for use of $\mathrm{P}_{\mathrm{SAG} 12^{-}}$ $I P T$ as a means of delaying leaf senescence in floriculture crops. 
The benefits gained by altering a given plant trait (like leaf senescence) through genetic engineering must be balanced with the potential change in horticultural performance of the plants. The positive progeny of I-3-18 demonstrated that the over-expression of cytokinins could delay the onset of leaf senescence in terms of leaf chlorosis and chlorophyll content. Since the apparent timing and amount of cytokinin production appear more tightly regulated in this line, the plants grow and develop like wild-type plants in terms of vegetative propagation, branching habit, and flower timing. These characteristics allow for the introduction of a desired trait (delayed leaf senescence) without compromising the horticultural performance of the plants. This work also demonstrates that the higher basal levels of IPT expression in positive segregants of I-1-7 cause a delay in leaf senescence but also alter some other horticultural characteristics. For example, I-1-7 plants exhibited increased branching during vegetative propagation and plant production. However, I-1-7 plants also showed a decreased ability to form adventitious roots on vegetative cuttings, which could be partially alleviated through the application of IBA.

The differences between the I-1-7 and the I-3-18 lines reflect a potential to select for desirable traits for a given transgenic plant event. Through the use of $\mathrm{P}_{\mathrm{SAG} 12}-I P T$ and a careful breeding and selection program, breeders can produce plants that possess the delayed leaf senescence phenotype that a consumer desires but not alter the production characteristics for that crop. Further experiments with $\mathrm{P}_{\mathrm{SAG} 12}-I P T$ plants should be focused on investigating other means of plant stress induction, such as nutrition or pathogen-induced stress. McCabe et al (2001) showed dramatic differences in nutrient

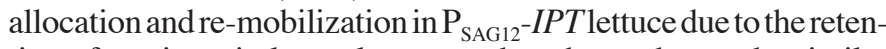
tion of nutrients in lower leaves, and we have observed a similar phenomenon in $\mathrm{P}_{\mathrm{SAG} 12}-I P T$ petunias (unpublished observation). Since these plants appear to differ in terms of the natural survival strategy of mobilizing stored reserves to flowering meristems, it will be imperative to examine these plants under outdoor field trial conditions in order to evaluate long-term garden performance under less than ideal environmental conditions.

\section{Literature Cited}

Akiyoshi, D.E., H. Klee, R.M. Amasino, E.W. Nester, and M.P. Gordon. 1984. T-DNA of Agrobacterium tumefaciens encodes an enzyme of cytokinin biosynthesis. Proc. Natl. Acad. Sci. USA 81:5994-5998.

Angra, R., and C.L. Mandahar. 1991. Pathogenesis of barley leaves by Helminthosporium-teres.1. Green island formation and the possible involvement of cytokinins. Mycopathologia 114:21-27.

Barry, G.F., S.G. Rodgers, R.T. Fraley, and L. Brand. 1984. Identification of a cloned cytokinin biosynthetic gene. Proc. Natl. Acad. Sci. USA 81: 4776-4780.

Buchanan-Wollaston, V. 1997. The molecular biology of leaf senescence. J.Expt. Bot. 48:181-199.

Chaudhury,A.M.,D.S.Letham, S.Craig, and E.S. Dennies. 1993.Amp1 - A mutant with high cytokinin levels and altered embryonic pattern, faster vegetative growth, constitutive photomorphogenesis and precocious flowering. Plant J. 4:907-916.

Chang, H., M.L. Jones, G.M. Banowetz, D.G. Clark. 2003. Overproduction of Cytokinins in Petunia Flowers Transformed with $\mathrm{P}_{\mathrm{SAG} 12}$-IPT Delays Corolla Senescence and Decreases Sensitivity to Ethylene. Plant Physiol. 132:2174-2183.

Chen, C.M. and D.K. Melitz. 1979. Cytokinin-autotrophic tobacco tissuecultures. FEBS Lett. 107:15-20.

Faiss, M., J. Zalubilova, M. Strnad, and T. Schmulling. 1997. Conditional transgenic expression of the ipt gene indicates a function for cytokinins in paracrine signaling in whole tobacco plants. Plant J. 12:401-415.

Gan, S. and R.M. Amasino. 1995. Inhibition of leaf senescence by autoregulated production of cytokinin. Science 270:1986-1988.
Gan, S. and R.M. Amasino. 1996. Cytokinins in plant senescence: From spray and pray to clone and play. BioEssays 18:557-565.

Hensel, L.L., V. Grbic, D.A. Baumgarten, and A.B. Bleecker. 1993. Developmental and age-related processes that influence the longevity and senescence of photosynthetic tissues in Arabidopsis. Plant Cell 5: 553-564.

Jordi, W., A. Schapendonk, E. Davelaar, G. M. Stoopen, C. S. Pot, R. De Visser, J. A. Van Rhijn, S. Gan, and R. Amasino. 2000. Increased cytokinin levels in transgenic $\mathrm{P}_{\mathrm{SAG} 12}-I P T$ tobacco plants have large direct and indirect effects on leaf senescence, photosynthesis and $\mathrm{N}$ partitioning. Plant Cell and Env. 23:279-289.

Jorgensen, R.A., P.D. Cluster, J. English, Q.D. Que, and C.A. Napoli. 1996. Chalcone synthase cosuppression phenotypes in petunia flowers: comparison of sense vs antisense constructs and single-copy vs complex T-DNA sequences. Plant Mol. Biol. 31:957-973.

Kakimoto, T. 2001 Identification of plant cytokinin biosynthetic enzymes as dimethylallyl diphosphate : ATP/ADP isopentenyltransferases. Plant Cell Physiol. 42:677-685.

Kaminek, M., V. Motyka, and R. Vankova. 1997. Regulation of cytokinin content in plant cells. Physiol. Plant. 101:689-700.

Klee, H.J. and M.B. Lanahan. 1995. Transgenic plants in hormone biology, p. 284-289 In: P.J. Davies (ed.). Plant hormones physiology, biochemistry, and molecular biology. $2^{\text {nd }}$ ed. Kluwer Academic Publ., Norwell, Mass.

Lohman, K.N., S. Gan, M.C. John, and R.M. Amasino. 1994. Molecular analysis of natural leaf senescence in Arabidopsis thaliana. Physiol. Plant. 92:322-328.

Matile,P., S. Hortensteiner, H. Thomas, and B. Krautler. 1996. Chlorophyll breakdown in senescent leaves. Plant Physiol. 112:1403-1409.

McCabe, M.S., L.C. Garratt, F. Schepers, W.J.R.M. Jordi, G.M. Stoopen, E Davelaar, J.H.A. van Rhijn, J.B. Power, and M.R. Davey. 2001. Effects of $\mathrm{P}_{\mathrm{SAG} 12}-I P T$ gene expression on development and senescence in transgenic lettuce. Plant Physiol. 127:505-516.

McKenzie, M.J., V. Mett, P.H.S. Reynolds, and P.E. Jameson. 1998. Controlled cytokinin production in transgenic tobacco using a copperinducible promoter. Plant Physiol. 116:969-977.

Medford, J.I., R. Horgan, Z. El-Sawi, and H.J. Klee. 1989. Alterations of endogenous cytokinins in transgenic plants using a chimeric isopentenyl transferase gene. Plant Cell 1:403-413.

Mok., M.C. 1994. Cytokinins and plant development-An overview, p. 155-166. In: D.W.S Mok and M.C. Mok (eds.). Cytokinins chemistry, activity, and function. CRC Press Inc., Boca Raton, Fla.

Noodén, L.D., J.J. Guiamot, and I. John. 1997. Senescence Mechanisms. Physiol. Plant. 101:746-753.

Noodén, L.D. 1988. The phenomena of senescence and aging, p. 2-50. In: L.D. Noodén and A.C. Leopold (eds.). Senescence and aging in plants. Academic Press Inc. San Diego, Calif.

Piruzian, E.S., V.M.Andrianov, V.M. Yusibo, and C.I. Pak. 1992. The effect of elevated cytokinin levels in transgenic tobacco plants on the activity of the chloroplast $r b c L$ gene, p. 103-109. In: M. Kamínek, D.W.S. Mok and E. Zažímalová (eds.). Physiology and biochemistry of cytokinins in plants. SPB Academic Publishing. The Hague, Netherlands

Smart, C.M., S.R. Scofield, M. W. Bevan, and T.A. Dyer. 1991. Delayed leaf senescence in tobacco plants transformed with $\mathrm{tmr}$, a gene for cytokinin production in Agrobacterium. Plant Cell 3:647-656.

Takei, K., H. Sakakibara, and T. Sugiyama. 2001. Identification of genes encoding adenylate isopentenyl transferase, a cytokinin biosynthesis enzyme, in Arabidopsis thaliana. J. Biol. Chem. 276:26405-26410.

Weaver, L.M., S. Gan, B. Quirino, and R.M. Amasino. 1998. Acomparison of the expression patterns of several senescence-associated genes in response to stress and hormone treatment. Plant Mol. Biol. 37:455-469.

Wintermans, J.F.G.M., and A. De Mots. 1965. Spectrophotometric characteristics of chlorophylls $\mathrm{a}$ and $\mathrm{b}$ and their pheophytins in ethanol. Biochim. Biophys. Acta 109:448-453.

Zubko E., C.J. Adams, I. Machaekova, J. Malbeck, C. Scollan, and P. Meyer. 2002. Activation tagging identifies a gene from Petunia hybrida responsible for the production of active cytokinins in plants. Plant $\mathrm{J}$. 29:797-808. 